\title{
Can we predict the health of teenagers 2 years in advance? A preliminary study
}

\author{
Nicolas Zdanowicz, MD, PhD* \\ Denis Jacques, MD, Psychiatrist \\ Christine Reynaert, MD, PhD** \\ * Joint clinic director, Professor of \\ psychiatry, in charge of adolescent \\ consultation and teaching at the faculty of \\ medecine (UCL). \\ ${ }^{* *}$ Professor of psychiatry, head of \\ department, in charge of department of \\ psychosomatic medicine (UCL). \\ BELGIUM
}

\begin{abstract}
Objective : A two year follow-up study of a cohort of adolescents on 9 health parameters.

Method : 325 adolescents were enrolled in April 1999. In addition to answering a general social-demographic questionnaire, they answered Wallston's Multidimensional Locus of Control scale (MHLC) and Olson's questionnaire on family dynamics (FACES III). 10 health indicators were recorded : two analogical visual assessments (VAS) (general coping and feelings of well-being), their concern for their health on a five level Likert scale, Zung's Subjective Depression Scale, and having had to repeat a school year as an indirect indicator of self esteem. Two years later, the sample $(n=86)$ were re-evaluated through the same questionnaires, and answered a supplementary questionnaire addressing (1) additional medication taken since their initial evaluation, (2) the number of medical consultations they have been through since the baseline, and/or (3) hospitalisations they underwent. They also answered a VAS about their level of concern over their body.

Results : Numerous variables belonging to Wallston's MHLC scale as well as to Olson's FACES III questionnaire were found to correlate with health indicators two years later. It proved to also be the case for both several « subjective » values such as general coping and feelings of well-being, and being concerned with one's health, and with more « objective » parameters such as subjects' scores on the "Subjective Depression Feelings" form, or their intake of additional medications.

Conclusion : It appears that it is may possible to predict two years in advance at-risk adolescents for whom preventive medicine is particularly necessary.
\end{abstract}




\section{Introduction}

About ten years ago, the development of preventive medicine became a major objective in many developed countries. The target populations that are aimed to benefit from these campaigns of prevention are teenagers, young adults, and their parents. The above populations being, "a priori", more likely to be influenced, and to adopt behaviours in favour of their health. However, what do we really know about the evolution of health at this age, and about its correlates with family dynamics ?

In previous studies (Zdanowicz et al. 2002a, 2002b, 2002c, 2002d, 2004a and 2004b) we were able to show marked differences between "healthy" adolescents, and a sample of adolescents presenting with a variety of mental disorders in terms of managing their own health issues, and family dynamics. In order to accomplish those studies, we used two tools : Wallston et al.'s Health Multidimensional Locus of Controle Scale (MHLC (1978)), and Olson's FACES III (1986) form on family dynamics. These 2 instruments were chosen because :

- The MHLC is one of the parameters which allows to predict if subject intends to realise a behaviour in favour of his/her health.

- Family dynamics is one of the cognitive variables able to influence the realisation of the behaviour.

The MHLC addresses the respondent's beliefs about his/her responsibility in determining his/her health. This scale is multidimensional in that it allows the identification of three different types of beliefs: One is « external», and two are « internal» in nature. Individuals with an internal locus of control believe that the positive reinforce- ments to which they are subject to depend upon their behaviour. This dimension is addressed by the subscale of Internal Health Locus of Control (IHLC). Individuals with an external locus of control either believe that their health is a matter of chance or fate, or results from a third party's action. The former attitude is addressed by the subscale of Chance Health Locus of Control (CHLC), and the latter by the subscale of Powerful others Health Locus of Control (PHLC). Finally, the relation between external and internal tendencies can be calculated through Internality/Externality ratio (Reynaert et al. 1995). The main criticism against this test is that there is a considerable gap between one's attitudinal Health Locus of Control and one's actual Behavioural concern about one's health (Conner et al. 1999). However, the point raised by this criticism was taken as an advantage in adolescence because during this period of life, young people often temporarily adopt behaviours that are detrimental to their health, and which undoubtedly reflect explorative attitudes and peer influences (tobacco, alcohol, etc.). Because of the gap between attitudes and behaviours, MHLC might reflect the respondent's disposition towards sustaining or abandoning these behaviours.

Olson's Circumplex Model aims at assessing two dimensions (axes) of the functioning of the relational system : cohesion and adaptability. Cohesion is defined on the basis of « emotional ties that each member of a family develops towards the other members ». Adaptability refers to the « ability of the marital or family system to change its power structure, roles relationships, and rules that are incumbent thereto in reaction to a situation or a stressful development». 
In our previous research, our two main findings concerning Health Locus of Control during adolescence were :

- That there are differences between « healthy » and « unhealthy » samples. « Unhealthy » subjects are markedly more dependent on others (PHLC), and on chance factors (CHLC), and show a lower level of Internal Health Locus of Control (IHLC), their I/E ratio being lower.

- That PHLC diminishes with age among « healthy » subjects.

Our two main findings concerning family dynamics during adolescence were:

- That « unhealthy » adolescents belong mostly to families with low levels of cohesion and adaptability.

- That among « healthy » subjects, family cohesion diminishes with age.

Finally, we have shown through the cross analysis of the two scales that the decrease of PHLC among "healthy" adolescents is correlated with the decrease in family cohesion.

\section{Hypothesis}

The question that has never been convincingly answered by previous research is: to what degree do we now possess information that can predict youth health? To answer this question, we performed a two-year follow-up study. Beginning with healthy subjects, we formulated the two following sets of hypotheses :

\section{1/ In connection to MHLC}

- The higher the initial PHLC, the worse health indicators are two years later.

- The higher the initial CHLC, the worse health indicators are two years later.
- The higher the I/E ratio, the more " optimistic » health indicators are two years later.

- The number of correlated health indicators decreases with time (PHLC $>$ CHLC $>$ Ratio I/E).

\section{2/ In connection to FACES IIII}

- High levels of family cohesion and of adaptability correlate with optimistic levels of health indicators.

- The number of correlated health indicators decreases with time (cohesion $>$ adaptability).

\section{Method}

The recruitment of the adolescent subject took place in April $1999(\mathrm{~N}=325)$, at which date they answered the first battery of tests. In April 2001, the second interview took place $(n=86)$.

Three standardised scales were used: MHLC, FACES III, and Zung's self rating of subjective depression (1965). The FACES III model is designed so that the two dimensions of family "health" are found in the median values of the two axes, that is to say the "separated-linked" dimension in the cohesiveness axix, and the "structured-flexible" dimension in the adaptability axis (hypothesis of a curvilinear correlation). The main criticism against this test questions the hypothesis of curvilinearity, and argues that a rather linear correlation might relate cohesiveness or adaptability to pathological states, at least when families presenting pathological cases are under observation (Smith 1997). In spite of this criticism, we decided to use this tool in light of the many studies that have used it and of 
the ability to compare our results with them (Zdanowicz et al. 2002d).

Other recorded parameters included :

1. One question on their general health concern : «In general, do you feel concerned about your health? » Subjects' answers were weighted on a 5 grade Likert-type scale (from « very little » to « very much »).

2. One question about their level of general coping : «I cope well with situations I find myself in » which was assessed on a VAS (from « absolutely wrong » to « absolutely true »).

3. One question about their general wellbeing : « I feel generally well in my day-today life » which was assessed on a VAS (from « absolutely wrong » to « absolutely true »).

In the 2001 follow-up study, five questions were added :

4. How many medications have you taken since April 1999 ?

5. Were you hospitalised since April 1999 ?

6. Over the last two years, how many times have you consulted a medical practitioner?

7. Are you concerned with your body? which was assessed on a VAS (from « absolutely wrong » to « absolutely true »)

8. One question on life events: « to what degree do you think that events in your life have played a role in your actual problems» which was assessed on a VAS (from « absolutely wrong » to « absolutely true »).

These 8 first questions together with the score on Zung's scale, and with a question measuring whether the subject had to repeat a school year in this two-year interval constituted the 10 indicators of health.

\section{Subject and procedure}

The recruitment of the sample took place in each of the 6 grades of three secondary schools (i.e. normally ranging from age 12 to $18 ; \mathrm{N}=101, \mathrm{~N}=98, \mathrm{~N}=126)$ in the province of Namur (Belgium). Under a psychiatrist's supervision, these adolescents were asked to answer a socio-demographic questionnaire (age, gender, high school level, nationality) as well as the various scales.

In order to further homogenise our samples, the subjects had to be Caucasian and French-speaking students.

Subjects were retested by mail in April 2001, and 249 of them did not respond. We think that the main reason for this weak rate is the change of setting for the signing. At baseline: in place of one of our of schools, at follow-up : out of school, at home.

\section{Analysis and results}

SPSS 10.0S Advanced Models for Windows was used for our statistical analyses. Given the considerable number of observations and the necessity to analyse the influence of several co-variables, we used parametric tests. Pearson's $\chi^{2}$ was used in comparing qualitative data; Student t-test was used in comparing means. Correlations between continuous variables were assessed through the use of multiple regressions controlled for age, gender, number of parents residing in the subjects' home, number of siblings (the two latter parameters having proved determining in previous studies) (Zdanowicz et al. 2002d, 2004b), and life events. Report between discrete variables have been calculated through the use of logistic regressions controlled for age, gen- 
der, number of parents residing in the subjects' home, number of siblings, and life events. Ranges of significance were as follows: $\mathrm{p} \leq 0.05$ indicates significance, and $\mathrm{p} \leq 0.01$ indicates a marked level of significance. All the statistics were calculated bilaterally while taking into account first and second order errors (CI 95\%). Results are displayed in the following order : Analysis of the demographic parameters, comparison of the 5 initial health parameters between the two years interval, comparison between respondents and non-respondents, influence of MHLC parameters and the family parameters on health indicators.

\section{Results}

\section{Demographic and health characteristics}

\section{Age, gender, and family composition}

As shown in Table I, there is no significant statistical difference between young subjects at time 1 and time 2 in terms of these parameters. We observe the same results when comparing respondents with non-respondents at time 2 except for gender where female subjects proved more participatory than their male counterparts.

Table I

Social-demographic comparisons at time 1 and 2

\begin{tabular}{lccccc} 
& Time 1 & Time 2 & $\begin{array}{c}\text { P (test) } \\
\text { T1/T2 }\end{array}$ & $\begin{array}{c}\text { Non } \\
\text { Respondents } \\
(\mathrm{NR})\end{array}$ & $\begin{array}{c}\mathrm{p} \text { (test) } \\
\text { T1/NR }\end{array}$ \\
\hline $\mathrm{N}$ & 325 & 86 & & 239 & \\
Average age & $15.3(\mathrm{SD} 1.8)$ & $17.4(\mathrm{SD} 1.8)$ & & $15.2(\mathrm{SD} 1.8)$ & $0.537(\mathrm{t}$-test $)$ \\
Sex ratio (F/M) & 1.47 & 1.15 & $0.210\left(\mathrm{x}^{2}\right)$ & 1.92 & $0.040\left(\mathrm{x}^{2}\right)$ \\
Live at home (\%) : & & & & \\
0 parents & 1.5 & 1.1 & $0.133\left(\mathrm{x}^{2}\right)$ & 1.4 & $0.778\left(\mathrm{x}^{2}\right)$ \\
1 parents & 17.8 & 23 & $0.299\left(\mathrm{x}^{2}\right)$ & 17.6 & $0.831\left(\mathrm{x}^{2}\right)$ \\
2 parents & 80.6 & 75.9 & $0.247\left(\mathrm{x}^{2}\right)$ & 80.5 & $0.352\left(\mathrm{x}^{2}\right)$ \\
0 Grandparents & 92 & 94.3 & $0.712\left(\mathrm{x}^{2}\right)$ & 91.6 & $0.242\left(\mathrm{x}^{2}\right)$ \\
1 Grandparents & 4.3 & 3.4 & $0.706\left(\mathrm{x}^{2}\right)$ & 4.7 & $0.866\left(\mathrm{x}^{2}\right)$ \\
2 Grandparents & 1.5 & 0.1 & $0.348\left(\mathrm{x}^{2}\right)$ & 1.3 & $0.979\left(\mathrm{x}^{2}\right)$ \\
3 Grandparents & 0.9 & 1.1 & $0.856\left(\mathrm{x}^{2}\right)$ & 1.3 & $0.703\left(\mathrm{x}^{2}\right)$ \\
4 Grandparents & 1.2 & 1.1 & $0.942\left(\mathrm{x}^{2}\right)$ & 1.1 & $0.652\left(\mathrm{x}^{2}\right)$ \\
Siblings (\%) : & & & & & \\
0 & 12.3 & 18.2 & $0.153\left(\mathrm{x}^{2}\right)$ & 13.5 & $0.814\left(\mathrm{x}^{2}\right)$ \\
1 & 35.3 & 42 & $0.250\left(\mathrm{x}^{2}\right)$ & 30.9 & $0.156\left(\mathrm{x}^{2}\right)$ \\
2 & 28.3 & 23.9 & $0.406\left(\mathrm{x}^{2}\right)$ & 28.3 & $0.771\left(\mathrm{x}^{2}\right)$ \\
3 & 17.2 & 13.6 & $0.419\left(\mathrm{x}^{2}\right)$ & 20 & $0.538\left(\mathrm{x}^{2}\right)$ \\
4 & 4.9 & 2.3 & $0.280\left(\mathrm{x}^{2}\right)$ & 4.8 & $0.860\left(\mathrm{x}^{2}\right)$ \\
$>$ & 1.8 & 0.1 & $0.557\left(\mathrm{x}^{2}\right)$ & 2.5 & $0.959\left(\mathrm{x}^{2}\right)$ \\
\hline
\end{tabular}

\section{Health status}

Regarding our health criteria that were recorded at time 1 and retested at time 2, Table II clearly shows that three of these criteria are worsening. This is particularly true regarding one's concern over one's health, which was previously evidenced in our country by Piette et al.' study (1997). Moreover, the adolescents who did not respond to the $2^{\text {nd }}$ test were those who presented the 
worst profile on Zung's subjective depression scale as well as on their general wellbeing questionnaire. This constitutes an advantage of our study on « healthy » subjects because it would mean that our proce- dure has selected the healthiest adolescents These teenagers had, in 2 year, on average: 3.9 medical consultations $(\mathrm{SD}=3.3), 0.18$ hospitalisations $(\mathrm{SD}=0.47)$ and $12 \%$ more of medicines.

Table II

Comparison between health statuses

\begin{tabular}{|c|c|c|c|c|c|}
\hline & $\begin{array}{c}\text { Time } 1 \\
\text { Mean (SD) }\end{array}$ & $\begin{array}{c}\text { Time } 2 \\
\text { Mean }(\mathrm{SD})\end{array}$ & $\mathrm{P}(\mathrm{t}$-test $)$ & $\begin{array}{l}\text { Non Respondents } \\
\text { Mean (SD) }\end{array}$ & $\mathrm{p}(\mathrm{t}$-test) \\
\hline Zung & $0.44(0.009)$ & $0.45(0.009)$ & 0.335 & $0.48(0,11)$ & 0.02 \\
\hline Concerened with health & $3.4(1.1)$ & $2.3(1.1)$ & 0.000 & $3.3(1.1)$ & 0.906 \\
\hline Life events & $4.5(2.9)$ & $4.6(2.9)$ & 0.882 & $4.8(3.0)$ & 0.353 \\
\hline General coping & $8.4(1.7)$ & $8.0(1.9)$ & 0.074 & $8.1(1.9)$ & 0.144 \\
\hline Well-being & $8.3(1.8)$ & $7.8(1.6)$ & 0.014 & $7.3(2.3)$ & 0.000 \\
\hline $\begin{array}{l}\text { Having had to repeat } \\
\text { a schoolyear }\end{array}$ & $\begin{array}{l}0.17 \text { year } \\
(0.38)\end{array}$ & $\begin{array}{l}0.61 \text { year } \\
(0.48)\end{array}$ & 0.000 & $\begin{array}{l}0.19 \text { year } \\
(0.39)\end{array}$ & 0.707 \\
\hline
\end{tabular}

\section{Hypotheses testing}

Our hypotheses are then (see above) that personal mechanisms of attribution in managing one's health, and the elements of family dynamics measured at time 1 of this research can successfully predict subjects' health status at time 2 . Instead of using a multiple stage design, we have chosen to use analyses that were controlled for co-variables (gender, number of parents, siblings, and life events) in order to include the most possible general view. The horizontal reading of these analyses of correlation in Table III shows that CHLC and family cohesion are very important predictive parameters. The vertical reading of these correlation analyses shows that it is « easier » to predict the level of subjective depression, followed by one's concern for one's health, followed by the level of wellbeing, and finally, by general coping and medication intake. Several variables are « unpredictable »: the number of academic failures, having being hospitalised, the level of one's concern over one's body, and the number of medical visits.

\section{Discussion}

In light of these results, two approaches seem warranted: one consists of comparing our results with these yielded by the international literature, and the second, in comparing them with our previous research results.

For the approach relying on the international literature, the discussion promises to be very short. Indeed, to our knowledge, only one prospective study utilizes health locus of control (Thomas et al. 1983), but it pertains to the probability of social integration of elderly people after 5 years as a function of their MHLC. This study showed that the dimension of « others' power » was proportionate to the respondents' insertion in a relational and medical care network. As a general rule, it is considered today that a 
Table III

Importance of the predictive factors

\begin{tabular}{|c|c|c|c|c|c|c|}
\hline \multirow{2}{*}{$\begin{array}{l}\text { Explaining } \\
\text { variables }\end{array}$} & \multirow{2}{*}{$\begin{array}{c}\text { Number of } \\
\text { explained } \\
\text { dependent } \\
\text { variables }\end{array}$} & \multicolumn{5}{|c|}{ Types of dependent variables ( $\mathrm{p}$ and $\beta$ or OR) } \\
\hline & & Zung & $\begin{array}{l}\text { Concerns } \\
\text { For health }\end{array}$ & $\begin{array}{l}\text { General } \\
\text { coping }\end{array}$ & Well-being & $\begin{array}{l}\text { Medications } \\
\text { added }\end{array}$ \\
\hline CHLC & 4 & $\begin{array}{l}\mathrm{p}<0.001 \\
\beta=0.437\end{array}$ & $\begin{array}{l}p=0.017 \\
\beta=-0.265\end{array}$ & $\begin{array}{l}p=0.007 \\
\beta=-0.318\end{array}$ & $\begin{array}{l}p=0.038 \\
\beta=-0.237\end{array}$ & \\
\hline Cohesion & 2 & $\begin{aligned} p & =0.002 \\
\beta & =-0.433\end{aligned}$ & & & $\begin{array}{l}\mathrm{p}=0.036 \\
\beta=0.245\end{array}$ & \\
\hline Adaptability & 1 & & $\begin{array}{l}\mathrm{p}=0.05 \\
\beta=-0.238\end{array}$ & & & \\
\hline PHLC & 1 & & & & & $\begin{aligned} \mathrm{p} & =0.037 \\
\mathrm{OR} & =1.246\end{aligned}$ \\
\hline Ratio I/E & 1 & $\begin{array}{l}p=0.01 \\
\beta=-0.297\end{array}$ & & & & \\
\hline IHLC & 0 & & & & & \\
\hline
\end{tabular}

feeble influence attributed to others is discretely correlated with adopting behaviours favouring health, and that an elevated level of belief in chance parameters is strongly and positively correlated with behaviours that are detrimental to health (Cobber et al. 1999). Our results concur with the international literature in this respect since in the MHCL, the belief in the chance factor, followed by the variable of depending on others, correlate with the largest number of dependent variables. FACES III results also concur with international research since when correlations could be established between pathologies and FACES III, they were first and foremost due to family cohesion and secondly, to adaptability levels (Zdanowicz et al. 2002d).

In comparing the present results with those yielded by our previous research, we were surprised in that the power attributed to others and family cohesion has, up until now, appeared to be the main factor in determining modification of the management of health issues during adolescence. On the other hand, it appears that the belief in chance factors - which was markedly higher among pathological young people as compared to control young people (see previous studies) - seems to predict « subjective » values (such as coping and well-being), as well as more « objective » values (such as feelings of depression). However, in the present study, the power attributed to others remains important since it is the only element that can be correlated with the use of medications two years later. We believe that if the number of answer, at the follow-up, had been more important other relations would have appeared on weaker percentage of explained variance.

\section{Limitations and conclusions}

This study is mainly limited by our relying on subjective VAS, which should be replaced with more objective scales in future studies, and by the weak number of responses at follow-up. In spite of this limitation, our study indicates that family 
dynamics, and health attributive parameters hold some predictive value of at least two years. The hope and the interest of this study rest in the fact that it enables the identifying of future at-risk young people. The results of the present research also complement other research such as Kapur et al.'s (2002) study on the number of adults' medical consultations as a function of their difficult childhood history, and Kroes et al.'s (2002) assessment of the social-familial predictive factors (such as: low-level parental occupation, having foreign-born parents, living in a single-parent family,...) of certain childhood mental disorders. Although these studies (including ours) shed some light on the identification and validity of importance of certain early conditions of life, they nevertheless leave a question unanswered : barring genetic predispositions, why does the same life event provoke different disorders in different individuals?

\section{References}

Conner M, Norman P. Predicting health behaviour. Buckingham-Philadelphia: Open University Press; 1999.

Kapur N, MacFarlane G, Creed F. Childhood experiences of adult frequent attenders in primary care: a case control study. Br J Psychiatry 2004;185(8):134-139.

Kroes M, Kalff AC, Steyaert J, Kessels AG, Feron FJ, Hendriksen JG, et al. A longitudinal Community study: do psychological risk factors and child behaviors checklist scores at 5 years of age predict psychiatric diagnoses at a later age? J Am Acad Child Adolesc Psychiatry 2002; 41(8): 955-963.

Olson DH. Circumplex model VII: validation studies and FACES III. Fam Process 1986; 25(3): 337-351.
Piette D, Prevost M, Boutsen M. Vers la santé des jeunes en l'an 2000 : une étude des comportements et mode de vie des adolescents de la Communauté française de Belgique de 1986 à 1994. Bruxelles: PROMES; 1997.

Reynaert Ch, Janne P, Delire V, Pirard M, Randour P, Collard E et al. To control or to be controlled? From Health Locus of Control to Morphine Control during Patient-Controlled Analgesia. Psychother Psychosom 1995; 64(2): 7481.

Smith SG. Clinical utility of the FACES III. Dissert Abs Intern: B : Sc and Eng 1997; 57: 7237

Thomas PD, Hooper EM. Healthy elderly: social bonds and locus of control. Res Nurs Health 1983; 6: 11-16.

Wallston KA, Wallston BS, De Vellis R. Development of the multimensionnal health locus of control scale. Health Education Monograph 1978; 6(2): 160-170.

Zdanowicz N, Coremans E, Reynaert Ch. Adolescences' depression: a trouble of internality[Abstract]. Eur Neuropsychopharmacology (2002d); 12(supplement 3): s173.

Zdanowicz N, Janne P, Reynaert Ch. Lieu de contrôle de la santé et prise en charge des adolescents. Rev Fr Psychia Psychol Méd 2002b; 54: 27-33.

Zdanowicz N, Janne P, Reynaert Ch. Role of the family during adolescence [Abstract]. J Psychosom Research 2002c ; 52(5): 373.

Zdanowicz N, Janne P, Reynaert Ch. Comparaison des attentes d'étudiants « sains » et « en souffrance » par rapport à leur famille. 2002a; 160(2) : 130-137.

Zdanowicz N, Janne P, Reynaert Ch. Family, health and adolescence. Psychosomatics 2004a; 45(6): 500-507.

Zdanowicz N, Reynaert Ch.. Adolescent health - second reply[letter]. The Lancet 2004b; 364(9433): 497.

Zung WK. A self rating depression scale. Arch Gen Psychiatry $1965 ; 12:$ 63-70.

Adrees of correspondence:

Université Catholique de Louvain

Clinique de Mont-Godinne

Service de psychosomatique

5530 Yvoir

Belgique - Belgium

Telephone : 00.32.81.42.37.51

Fax : 00.32.81.42.37.51

e-mail : nicolas.zdanowicz@pscl.ucl.ac.be 